\title{
Imagination and Perception in Film EXPERIENCE
}

\author{
ENRICO TERRONE \\ LOGOS Research Group, Universitat de Barcelona
}

\begin{abstract}
Reporting one's experience of the film Alien, one might say that one saw Warrant Officer Ellen Ripley fighting the monster, but one might also say that one imagined Ripley fighting the monster. This paper aims to figure out the experience that the verbs "to see" and "to imagine" characterize in such reports. For this purpose, I first introduce four requirements for an account of film experience. Secondly, I examine the main theses on the role of imagination and perception in film experience, arguing that none of them satisfies all the requirements. Thirdly, I propose a new thesis according to which the spectator of a fiction film imagines being a subject of a different kind, namely, a disembodied subject of experience who can perceive events that occur in a world in which that subject has no place. I argue that this thesis satisfies all the requirements.
\end{abstract}

B отн perception and imagination seem to play a crucial role in our engagement with fiction films but whether they really do so, and which role they possibly play, is controversial. On the one hand, a fiction film, as film, is a depiction that invites us to perceive the events portrayed. On the other hand, as fiction, it invites us to imagine the story told. Thus, after watching the film Alien (1979), one might say that one saw Ripley fighting the monster but one might also say that one imagined Ripley fighting the monster. Are these two reports compatible? If they are, how can we combine them so to make sense of them? If, instead, they are not, which of them should we give up?

In order to answer these questions, we need, first of all, to specify what we mean by 'perception' and 'imagination' and how we distinguish them. Among the traditional criteria for distinguishing perception from imagination, Shen-yi Liao and Tamar Gendler (2019: §2.3) mention intensity, involuntariness, and causal relationship with the relevant object. In his "Sartrean Account" of per-

Contact: Enrico Terrone < enriterr@gmail.com> 
ception and imagination, Uriah Kriegel (2015) proposes another criterion: these two kinds of mental states can have the same content but differ as regards their attitude. For instance, I can see an apple falling from a tree as well as imagine an apple falling from a tree. Although these mental states have the same content, they differ as regards the way in which they relate it to me as the subject of experience, namely, their attitude.

Specifically, according to the attitudinal approach that I use to characterize film experience, the attitude of perception represents its content (for instance, the apple falling) as occurring here and now, in front of me, in a spatiotemporal structure that includes myself as the subject who is perceiving. The attitude of imagination, instead, represents its content as occurring in an alleged alternative spatiotemporal structure that does not include myself as the subject who is imagining. ${ }^{1}$

Given this distinction, how can we characterize film experience? When I watch Alien in a movie theater, there is a sense in which I experience Ripley fighting the monster here and now, in front of me, as a publicly accessible event which other subjects who now are here in the movie theater also can experience. This publicity distinguishes film experience from a paradigmatic case of imagination such as mental imagery, which is essentially private. Thus, I might feel entitled to report that I saw Ripley fighting the monster even though I do not feel entitled to report that I saw the pink elephant that I was visualizing on my own.

Nevertheless, while watching Alien I also acknowledge that Ripley is not fighting the monster here and now in the same sense in which, say, the spectator in a nearby seat is munching popcorn here and now. First, I can interact with this spectator but not with Ripley and the monster. Secondly, I am aware that Ripley and the monster, unlike the popcorn muncher, do not exist. Thus, I might feel entitled to report that, while I surely perceived the popcorn muncher, I rather

1. The notion of spatiotemporal structure I use to distinguish between perception and imagination draws on Peter Strawson's notion of a "spatiotemporal framework" that enables our experiences and allows us to share them through discourse: "We can make it clear to each other what or which particular things our discourse is about because we can fit together each other's reports and stories into a single picture of the world; and the framework of that picture is a unitary spatiotemporal framework, of one temporal and three spatial dimensions" (1959: 38). In perception the spatiotemporal structure includes myself in the sense that I experience events as occurring in front of me simultaneously with my experience. In memory the spatiotemporal structure also includes myself in the sense that I experience events as occurring at a time that precedes my experience, and such relation of temporal precedence warrants that the remembering subject and the events remembered belong to the same spatiotemporal structure. Imagination, instead, represents events as occurring in an alternative spatiotemporal structure that is not that in which the imagining subject has his or her place. At most, this subject might represent an alternative version of him or her in that structure, as for instance when I imagine myself walking on the moon. Yet, in this imaginative scenario, I am not walking on the moon and imagining doing so. I am just walking. Conversely, if I perceive myself walking on the moon, I am walking on the moon and perceiving doing so. Thanks to a referee for leading me to clarify the notion of imagination on which my paper relies. 
imagined Ripley and monster, that is, I experienced Ripley fighting the monster in a spatiotemporal structure that did not include myself.

To sum up, film experience seems to lie between perception and imagination. Experiencing Ripley fighting the monster is more perceptual than a paradigmatic imaginative experience such as visualizing a pink elephant "with the eye of the mind", and yet more imaginative than a paradigmatic perceptual experience such as perceiving a popcorn muncher in a nearby seat. However, lying between perception and imagination is just a metaphor, and one should unpack it if one wants to figure out the role that imagination and perception play in film experience.

Philosophers have proposed settling this issue in three different ways. A first approach (see Matravers 2014) states that film experience essentially is a matter of perception while imagination plays no essential role even when we watch fiction films. A second approach (see Currie 1995) states that, even though film experience as such is perceptual, when we watch fiction films perception boils down to the input of an essentially imaginative experience. A third approach (see Wilson 2011) states that both imagination and perception play an essential role in our experience of fiction films.

The latter approach relies on the fact that one can include oneself in one's imaginings. I can imagine not only an apple falling from a tree but also myself falling from a tree. Although the imagined scenario cannot actually include myself as the subject who is imagining, it can include an alternative version of me who is not imagining but just falling from a tree. Imagination essentially differs from perception in this respect. If I imagine falling, in my imagined scenario I am not falling while imagining doing so. If, instead, I perceive myself falling, I am falling while perceiving doing so.

Such a capacity of including the subject of experience in the imagined scenario provides us with a way of combining imagination and perception in our engagement with fiction films. Perception can be embedded into the imagination. For instance, I can report my experience of Alien by saying that I imagined seeing Ripley fighting the monster. This approach to film experience seems capable of giving due consideration to both perception and imagination, but it confronts important problems, which my paper shall point out and try to solve.

Specifically, I shall proceed in three steps. First, in Section I, I highlight four requirements, which an account of film experience must satisfy. Secondly, in Sections 2-4, I examine the three main philosophical theses on imagination and perception in film experience that have been proposed so far, and I argue that they do not satisfy all the requirements. Thirdly, in Sections 5-8, I propose a fourth thesis and argue that it provides a better fit to the requirements than its rivals, and that it can also accommodate other relevant features of film experience. 


\section{Four Requirements}

As a starting point of this paper, I assume that any account of the role of imagination in our engagement with fiction films must satisfy the four requirements I am going to highlight. The first three come from the role of perception in film experience, while the fourth one comes from the very notion of fiction film. Relying on these requirements will make my conclusion a conditional: if the four requirements hold, then my account is better than its rivals. Still, there seems to be intuitive support for these requirements so that one might be inclined to endorse them, and this would turn my conclusion into a full-fledged assertion.

The four requirements are the following.

\section{i) Seeing-in: Film experience involves a perceptual experience of the things depicted.}

I call this requirement Seeing-in, but I am not committing myself to Richard Wollheim's (1980) account of seeing-in or to any alternative conception of pictorial experience. What I call 'Seeing-in', here, is just the fact that we have a perceptual experience of the things we see in a film. This experience is perceptual inasmuch as it provides us with a perspective on mind-independent and publicly accessible things, which are arranged in a spatial structure involving a range and possibly obstructions (cf. Alsmith 2017; Martin 1992; Strawson 1974). Such perspective allows us to gather sensory information about things just as we do in ordinary perception.

Film experience is closer to ordinary perception than the experience of static pictures, because it represents things in a structure that has not only a spatial dimension but also a temporal one. In this way, it can provide us not only with visual information but also with auditory information. Moreover, it enables us to not only to perceptually identify individuals but also to re-identify them, just as we do in ordinary perception. ${ }^{2}$

2. Still, in the case of fiction films, one might wonder whether we are entitled to speak of a perceptual experience in the absence of one of the hallmarks of perception, namely, factivity, the property of entailing that what is perceived actually is the case. If one takes factivity to be an essential feature of any perceptual experience, then the experience of fiction films cannot be treated as a perceptual experience and boils down to a perception-like experience. However, this experience would be closer to perception in a stronger sense than a paradigmatic perception-like experience such as mental imagery. The point is that film experience, unlike mental imagery, shares with perception the will-independence and the public accessibility of its objects. In this sense, film experience provides us with an "impression of perceiving" things even though those things do not exist (cf. Lopes 1998: 348-349; Wilson 2011: 60-71). That is why I will keep using the expression 'perceptual experience'. In the philosophical debate on seeing-in, one can find some ways of figuring out such impression of perceiving, e.g., experienced similarity, neutralized illusion, perception penetrated by the imagination (for a survey, see Voltolini 2015: 57-124). Thanks to a referee 
ii) Detachment: The film spectator perceives things from a standpoint that she does not experience as occupied by her body.

Film experience, as perceptual experience, exhibits a key difference with respect to ordinary perception. In the latter, we experience things as located in our egocentric space, that is, in the spatial system that has our body as its own center. In film experience, we perceive things as having their place in a spatial system that has the same perspectival structure as our egocentric space, and yet the center of such system is not experienced as occupied by our body. Following Noël Carroll (1996: 70), I call this requirement Detachment since it involves that the things we see in a film are experienced as detached from our body. Perceiving things in this way involves acknowledging that we cannot interact with them in the way in which we normally do in ordinary perception. Detachment thus distinguishes film from immersive virtual reality (for instance, the Oculus Rift system), which emulates perception in a stronger way than film precisely by providing the beholder with the experience of an egocentric space.

iii) Collapse: Although a fiction film is actually a depiction of a staged representation of fictional events, the spectator can experience the film directly as a depiction of fictional events.

The experience of fiction films involves a phenomenon that Robert Hopkins (2008) has pointed out and named "Collapse". Most fiction films, in fact, depict staged representations of fictional events, and spectators know this. Nevertheless, in watching a fiction film, spectators can have the impression of directly experiencing a depiction of fictional events. That is to say that, at the phenomenological level, the staging tier disappears - or, in Hopkins's terms, collapses.

It is worth noting that Collapse does not entail that film spectators are undergoing an illusion of perceiving the fictional events without any representational mediation. Even if the staged representation collapses, the pictorial representation remains crucial to film experience. Therefore, Collapse does not prevent spectators from paying attention to the features of the film as a representation, namely, features such as framing or editing. ${ }^{3}$

for drawing my attention to the distinction between perceptual experiences and perception-like experiences.

3. We can appreciate framing or editing while engaging with a pictorial representation of fictional events just as we can appreciate these features while engaging with a live television broadcast or a documentary, namely, with pictorial representations of actual events. Still, Malcom Turvey (2019) argues that Collapse would prevent spectators from appreciating actors' performances. This is true, but only in the sense that when one perceives a fiction film as a pictorial representation of fictional events, one cannot notice actors' performances by relying only on one's perceptual experience. That is why mockumentaries (fiction films that the audience can mistake for docu- 
iv) Disconnection: In watching a fiction film, the spectator locates events in a spatiotemporal system such that there is no spatiotemporal route that connects it to her world.

As spectators of fiction films, we enjoy events as if they occurred in a spatiotemporal system which is not the one we inhabit (at most, it is an alternative version of ours). We treat that system and ours as disconnected, that is, we neither believe nor imagine that there is any spatiotemporal route that connects them. That is why I call this requirement Disconnection.

The latter requirement is not to be confused with Detachment, which concerns our engagement with any film, not only with fiction films. In watching a documentary or a live television broadcast we enjoy Detachment but not Disconnection. Detachment and Disconnection go together only in our engagement with fiction films.

On the one hand, Detachment makes us perceive the space portrayed by a film as detached from our egocentric space, and yet does not prevent us from treating these two spaces as two regions of one unitary space that are connected by some spatiotemporal route. Disconnection, on the other hand, prevents us from doing so, thereby leading us to treat the spatial region where fictional events occur as situated in a world that no spatiotemporal route can connect to ours. ${ }^{4}$ From this perspective, Disconnection captures what Kendall Walton calls "our original feeling that fictional worlds are somehow insulated from the real world" (1978: 17).

In the first instance, Disconnection applies to the relationship between the fictional world and the actual world, but this is trivial since we are all well aware that there is no spatiotemporal route connecting our actual world to the fictional world. More importantly, Disconnection also applies to the relationship between the fictional world in which we imagine fictional events to occur and whatever supplementary world (that is, whatever alternative version of our actual world that is also distinct from the fictional world) we might imagine to inhabit while watching a fiction film. As Gregory Currie puts it, "In most films, the possibility that the events of the story could be literally seen from another world is ruled out" (2004: 98). Seeing an event E from a place $P$, indeed, requires a spatiotemporal connection between $\mathrm{P}$ and the place where E occurs, but the fictional world,

mentaries) are possible. Nevertheless, one can effectively appreciate actors' performances if one supplements one's perceptual experience of a fiction film with non-perceptual information about the history of making of that film. Thanks to a referee for drawing my attention to these issues.

4. Even if the events of a fiction film occur in an allegedly real place and time (for instance, Paris 1959 in Jean-Luc Godard's Breathless), they do not occur in our own spatiotemporal system, and we are aware of that inasmuch as we are aware that in no way we could have attended those events. Not even a time machine would allow us to attend them. 
as world, is a unitary spatiotemporal manifold whose places are connected to nothing but other places of it. That is why the events of the story cannot be seen from another world. Ultimately, one can see fictional events only if one has a place in the same fictional world in which those events occur.

With these four requirements in mind, I shall examine the three main theses on the role of imagination in our engagement with fiction films that have been proposed in contemporary analytic aesthetics. These are the following:

- No Imagining: Imagination plays no essential role in our engagement with films.

- Impersonal Imagining: The spectator imagines only that the fictional events occur, not her perceptual relation to them.

- Imagining Seeing: The spectator imagines not only that the fictional events occur but also that she personally perceives them.

After arguing that these theses cannot satisfy all the four requirements, I shall propose and defend a new thesis that can satisfy them all:

- Imagining Impersonal Seeing: the spectator imagines that the fictional events occur, that she perceives them, and that she does so in an impersonal way.

\section{The No Imagining Thesis}

According to what I call "The No Imagining Thesis" (No Imagining for short), our experience of films comes down to a perceptual experience in which imagination plays no essential role. Derek Matravers (2014) defends this thesis drawing on Seeing-in and Collapse. Their combination leads him to conclude that the spectator does not need to imagine the fictional events, since she already has a perceptual experience of them: "the audiences will have access to the story told without recourse to the imagination. They simply look at the cinema screen and the narrative is there to be seen" (Matravers 2014: 154).

Still, this view is at odds with Detachment, which introduces a key difference between ordinary perception and film experience. While in ordinary perception we experience events as taking place here and now, in a spatial system that includes ourselves, in film experience we are left with the need to situate the perceived events with respect to ourselves and the spatial system we inhabit.

In non-fiction films this need is fulfilled by the spectator's beliefs about the causal chain that connects what is perceived to what was filmed. But, in fiction films, this solution is ruled out by Collapse, which removes the staged representation from the spectator's experience. Since the staged representation is a cru- 
cial link of the causal chain that connects what is perceived to what was filmed, removing this link prevents the spectator from exploiting that chain.

In sum, Detachment leaves us with the need to situate the perceived events with respect to our spatial system, and Collapse prevents us from exploiting beliefs about causal chains in order to fulfill this need. In fact, in order to properly understand the events we are seeing, we need to know where and when they are occurring. In ordinary perception, the questions "where?" and "when?" are answered by perception itself, which informs us that what we perceive is occurring here and now. In watching a non-fiction film, we can answer these questions by means of knowledge about the causal chain that has led to the production and screening of this film. Thus, the answer to the question 'where?' is 'somewhere in our actual world', and the answer to 'when?' is 'at some moment in the past' (or 'now' if we are watching live television). But what about fiction films? Imagination provides us with an answer: the events we see have their place and time in a spatiotemporal system different from ours that we are invited to imagine. In this sense, imagination plays an essential role in our engagement with fiction films.

Matravers tries to avoid resorting to imagination by relying on the notion of a mental model: "understanding a narrative is a matter of working out the content of the narrative from its surface structure. In working it out, we form a mental model" (2014: 155-156). Yet, a mental model is a representation of states of affairs that is neutral with respect to whether those obtain or not in our actual world. This leads Matravers to state that "Our understanding of a narrative does not change if we shift from thinking of it as a fiction to thinking of it as a documentary" (2014: 156).

In fact, watching a fiction film and watching a documentary involve similar cognitive processes in the sense that both experiences comply with Detachment, thereby differing from ordinary perception, which gives us access to an egocentric space where we can act. In Matravers's terms, both experiences are instances of "representation", not of "confrontation" (2014: 47). Nevertheless, not all representations are at the same level. There is a crucial difference between engaging with a representation of an event with which we are connected in virtue of being in the same spatiotemporal system and engaging with a representation of an event that occurs in an alleged spatiotemporal system disconnected from ours. Seeing a nuclear explosion in a science fiction movie is not the same as seeing it in a live television broadcast, though both are cases of representation instead of confrontation. It is true that Detachment matters, but Disconnection also matters. Still, a mental model, as such, just represents events as detached from our egocentric space with no stance on whether they are located in our spatiotemporal system or in another that is disconnected from ours. Therefore, the mental model based account of film experience only fits with Detachment, not with Disconnection.

Matravers's account might well describe a basic stage of information pro- 
cessing at which the spectator just forms a mental model that does not specify whether events are represented in her spatiotemporal system or in a spatiotemporal system disconnected from hers. Yet, a thorough account of film experience must also consider how the spectator relates herself to the events represented. Spectators surely are not content to only know that the events they see are not occurring here and now in their immediate surroundings. In order to properly experience a film, one needs to know whether the events one sees on the screen occur in one's world or in an alleged spatiotemporal system disconnected from one's own. Specifically, the spectator of a fiction film needs to situate events in the latter system. Yet, a mental model, as such, does not enable one to do so since it just represents events without taking any stance on the spatiotemporal system in which they occur. The imagination, by contrast, in virtue of its distinctive attitude, represents events as occurring in a spatiotemporal structure that does not include the subject who is imagining. Therefore, imagining enables the spectator of fiction films to carry out an indispensable cognitive task (i.e., situating the event she perceives in a world that is not hers) that she could not fulfill by only resorting to mental models. That is why No Imagining must be rejected. ${ }^{5}$

\section{The Impersonal Imagining Thesis}

According to what is usually called "The Impersonal Imagining Thesis" (Impersonal Imagining for short), the spectator imagines that the events she recognizes in the film occur in a fictional world, and that is all. The spectator does not imagine that she perceives those events. The imagination at work is thus 'impersonal' since it does not involve any imagining about the person who is imagining. As Currie puts it,

What I imagine while watching a movie concerns the events in fiction it presents, not any perceptual relations between myself and those events. My imagining is not that I see the characters and the events of the movie; it is simply that I imagine that these events occur - the same sort of impersonal imagining I engage in when I read a novel. (1995: 179)

5. A slightly different version of No Imagining is proposed by Robert Stecker (2013), who argues that we just need Seeing-in and Detachment in order to explain the experience of the fictional events that a film presents. According to Stecker, Seeing-in allows spectators to have a perceptual experience of an event while Detachment exempts them from treating that event as real, thereby allowing them to treat it as fictional. Nevertheless, Seeing-in and Detachment hold not only for fiction films but also for non-fiction films and for live television. Relying on these features of film experience is not enough. Something more is needed in order to turn film experience into an experience of fictional events. That is why a proper account of the experience of fiction films cannot help but resort to the imagination. 
What motivates Impersonal Imagining is that imagining perceiving fictional events would involve imagining a spatiotemporal route that leads from those events to the spectator, but such route is not something that a film normally mandates us to imagine. As specified by Disconnection, the fictional world, as such, is meant to be completely disconnected from our world, and a film does not normally mandate us to imaginatively reconstruct such an impossible connection.

Still, in virtue of Seeing-in and Collapse, the spectator actually enjoys a perceptual experience of the events depicted. Even if a fiction film does not explicitly invite us to imagining perceiving fictional events, such an imagining results from the combination of what the film invites us to imagine (i.e., that the events depicted occur in a fictional world) with the phenomenology of film experience (according to which we enjoy a perceptual experience of the events depicted). The imaginary relation between our perceptual experience and the fictional events is not something that we must deliberately construct in our imaginative project. It comes for free as a result of the combination of our imaginative project with Seeing-in and Collapse. This is, so to say, a gift that the spectator finds it hard to refuse.

That being the case, a defender of Impersonal Imagining could reject Seeing-in or Collapse. If one rejects Seeing-in, one is committed to an account of film experience according to which the spectator only enjoys a perceptual experience of colored patterns on a screen by means of which she comes to imagine that some events occur in the fictional world. This seems to be at odds with the phenomenology of film experience. ${ }^{6}$

Alternatively, one can accept Seeing-in and just reject Collapse. In this case, the spectator has a perceptual experience of actors playing in the real world that she exploits to imagine that certain events occur in the fictional world. Such a version of Impersonal Imagining is defended by Colin McGinn (2005) and Noël Carroll (2009). Still, giving up Collapse remains a high price to pay since film ex-

6. Furthermore, giving up Seeing-in makes it hard to explain how spectators can appreciate the sensory features of the things depicted. Indeed, one cannot state that spectators exploit the colored patterns on the screen to form mental images, since this is at odds with empirical data. The reason is that the brain areas activated by vision and visual imagery are significantly overlapping. On the functional level this means that the same cognitive mechanisms are recruited both to see and to visually imagine something. The consequence, as shown by several empirical studies (for a review see Currie \& Ravenscroft, 1997), is that a mechanism recruited by vision cannot be recruited at the same time in order to visually imagine. Therefore, the mere fact of paying attention to the screen prevents spectators from forming mental images of fictional events. That being the case, visual imagery cannot be the form of imagination that is crucial to film experience. Although film experience involves a sensory format, this is not the same as that of visual imagery inasmuch as it does not originate from "the eye of the mind" but rather from the eyes of the body. This fact helps us to understand why people who are unable to create visual images in mind - a condition called "aphantasia" (see Zeman, Dewar, \& Della Sala 2015) - do not find themselves unable to appreciate films. Thanks to a referee for drawing my attention to the case of aphantasia. 
perience seems to involve something more immediate than just watching moving pictures of a play-something special that Jerrold Levinson characterizes as "The immediacy of our involvement in, and our extraordinary capacity to be affected, cognitively and emotionally, by cinema viewing" (2016: 173). Moreover, treating film experience as nothing but an experience of moving images of a play would prevent us from properly differentiating the experience of fiction films from that of broadcasts of theater or opera (for instance, the "Metropolitan Opera Live in $\mathrm{HD}^{\prime \prime}$ ).

Another option for the defender of Impersonal Imagining consists in accepting both Seeing-in and Collapse, thereby acknowledging that the spectator enjoys a perceptual experience of fictional events, and yet holding that this experience is, in some sense, excluded from the imaginative project. In this way, the spectator imagines that fictional events occur, and she can also imagine their sensory features by exploiting the sensory information provided by her experience. 7 Yet, the spectator does not imagine perceiving fictional events, in spite of undergoing a perceptual experience of them. That is to say that, although the spectator has the impression of perceiving fictional events, she leaves this impression out of her imaginative project. The perceptual gift is imaginatively refused, as it were.

This option can take into account the intimate relationship between perception and imagination in the experience of fiction films - a relationship that is acknowledged by both Dominic Lopes (1998) and Gregory Currie and Ian Ravenscroft (2002) in their discussions of Impersonal Imagining. Yet, this option requires that the spectator engages in a supplementary imaginative effort in order to prevent her impression of perceiving fictional events from entering her imaginative project. This does not seem to be a task that we usually carry out while watching fiction films. ${ }^{8}$

The defender of Impersonal Imagining might reply that the spectator does not need to make an effort in order to leave the perception of fictional events out of her imaginative project since that alleged perception occurs only at a subpersonal level. But this leads us back to the violation of the Seeing-in requirement, according to which the spectator enjoys a perceptual experience of the

7. In other words, the spectator can exploit the sensory information provided by her experience to simulate the grasping of "perceptual facts" (see Byrne 2010: 24-25) and the formation of "perceptual beliefs", thereby forming "perceptual imaginings" (see Currie 1995: 183-185; Gaut 2010: 209-217). Thanks to a referee for drawing my attention to these notions.

8. Moreover, the appreciation of certain point-of-view shots requires the impression of perceiving fictional events as an element of the imaginative project (cf. Gaut 2010: 217). Currie himself acknowledges this point in a later essay in which he analyses the point-of-view shot in the ending of Ingmar Bergman's A Passion (1969): "I must now acknowledge defeat [ . . . ] we have a positive reason to accept the thesis of imagining seeing [ . . . F For we need to say that the function of such an element is to enable a viewer to think, of their own (imagined) seeing of the fictional events, that it is like the character's visual experience" (2010: 334 ). 
things depicted. If the purported perception of fictional events only occurred at a sub-personal level, it could not show up in film experience, as required by Seeing-in.

\section{The Imagining Seeing Thesis}

According to what is usually called "The Imagining Seeing Thesis" (Imagining Seeing for short), in watching a film the spectator imagines that she is perceiving the fictional events that the film depicts. Still, there are two different ways of figuring out what 'perceiving' means in the latter sentence. We can interpret 'perceiving' either as ordinary face-to-face perception or as "transparent" pictorial perception (see Walton 1984), that is, something like the perception of real events through live broadcast or recordings.

If one chooses the former option, imagining seeing fictional events entails imagining occupying the standpoint from which those events are seen. Yet, this kind of imagining requires something more than just indulging in the impression provided by Seeing-in and Collapse, that is, the impression of seeing fictional events. The latter experience, as specified by Detachment, presents a space detached from the spectator's egocentric space. Still, if the spectator wants to imagine her pictorial experience to be ordinary face-to-face perception of fictional events, she must deliberately imagine her body to be at the standpoint from which she sees the fictional events. This imaginative project would require turning her actual experience of a detached space into an imagined experience of an egocentric space, with the appropriate cluster of visual, tactile, kinaesthetic and other experiences that one would enjoy in those circumstances. Yet, we do not usually make such an imaginative effort while watching fiction films.

Furthermore, as pointed out by Currie (1995), this kind of imagining might have two awkward side-effects. First, in most films the spectator should imagine not only being in the fictional world, but also to relentlessly change her position within it. Given that most fiction films have an "average shot length" of less than ten seconds, the spectator should imagine suddenly changing her position within the scene at least every ten seconds. This strengthens Currie's point that "a viewer who did imagine all this would be so mentally occupied as to be scarcely able to attend to the film" (1995: 172). Second, if the spectator imagines seeing any fictional event shown in the film, then she cannot imagine that an event shown in the film is in fact unseen. Yet this imaginative impossibility seems in contradiction with what some films mandate us to imagine (see Currie 1995: 173).

In order to avoid such consequences, one might interpret Imagining Seeing as claiming that the spectator imagines enjoying a "transparent" pictorial percep- 
tion of fictional events. George Wilson (2011) develops this option in what he calls "The Mediated Version of the Imagining Seeing Thesis."

According to Wilson, the spectator imagines that the events depicted occur in the fictional world and that she perceives them, but she does not imagine occupying the standpoint from which these events are perceived. Instead, she imagines seeing fictional recordings of the fictional events. As Wilson puts it, "We imagine and we are intended to imagine that we are shown a selection of motion picture shots of fictional characters and their deeds" (2011: 45).

In this version of Imagining Seeing, the spectator does not apply her imagination to her experience of the film screened, which remains a pictorial experience also in the imaginative project, but rather to the film itself, which she imagines to be a fictional recording of fictional events. The pictorial experience is thus imaginatively modified only in the sense that its object, the film, is imaginatively modified.

The "Mediated Version" of Imagining Seeing satisfies Seeing-in, Detachment and Collapse, but is in tension with Disconnection, since this version still presupposes that there is a spatiotemporal route that connects the fictional events to the spectator through the fictional recording. The spectator is no longer in front of the fictional events, but she imaginatively enjoys pictures that come from the places where these events occur. In Wilson's terms, "we imagine the actual shot as having a kind of causal origin that we know it really did not have" (2011: 100).

One might ask who produced those pictures and how. The presence of a cameraman or a hidden camera in the places where the fictional events occur seems to be in contrast with what most fiction films mandate us to imagine. Wilson addresses this objection by arguing that "It is fictional that imagined shots were not taken by a camera at the fictional scene, and it is otherwise indeterminate how fictionally they came to be" (2011: 47). There is no fact of the matter as regards how the fictional recordings were produced and made available to the spectators. In this sense, asking who produced those recordings and which technology was exploited in their production and distribution amounts to raising what Walton calls "silly questions" (1990: 174-183).

Nevertheless, according to the imaginative project required by Wilson's interpretation of Imagining Seeing, it is not indeterminate that the spectator has her place in an environment in which the recordings of the fictional events are screened. Therefore, because of the very notion of a recording, it is not indeterminate that there is a spatiotemporal route that goes from the fictional events to the spectator through the screening of the film. The indeterminacy to which Wilson appeals only concerns how this route came to be, not the fact that there is this route. The latter fact suffices to violate Disconnection, according to which in watching a fiction film we do not imagine that there is any route connecting the fictional world to the spectator's spatiotemporal system. The only way to avoid 
violating Disconnection would consist in specifying that the spectator imagines seeing recording of fictional events from within the same fictional world in which those events occur. Yet, in this imaginative project, the spectator should imagine not only the screened film to have some causal origin in the fictional world, but also the movie theater to have some (albeit indeterminate) spatial location in that world. This would be a cumbersome imaginative task, which does not seem to play any role in our experience of fiction films.

The difficulty with Disconnection also affects Angela Curran's (2016) attempt to amend Wilson's account by stating that indeterminacy does not concern the way in which the fictional recordings are produced. According to Curran, what is indeterminate is - more generally - the way in which the spectator has perceptual access to the fictional world. Still, also in this case, indeterminacy only concerns how the spectator has perceptual access to the fictional world, not that she has such access. Since the notion of perceptual access involves a spatiotemporal route connecting the spectator to the fictional world, the mere availability of this access contradicts Disconnection, regardless of the indeterminacy of the way in which this access is obtained.

A similar problem pops up in Walton's (1990) defense of Imagining Seeing. Walton relies on the distinction between a "work-world", in which the spectator does not exist, and a "game-world", which is instead imaginatively inhabited by the spectator who, from there, enjoys a perceptual access to fictional events. According to Walton, it remains indeterminate how this perceptual access is gained. Yet, this perceptual access, as such, would involve a spatiotemporal route that connects the work-world to the game-world, thereby violating Disconnection. In fact, Walton can avoid this problem by conceiving of the game-world as a slightly modified version of the work-world in which the spectator is included as an eyewitness of the fictional events. However, imagining being an eyewitness would involve imagining face-to-face perceiving fictional events, thereby leading the defender of Imagining Seeing back to the problems that I pointed out earlier at the beginning of this section. 9

Levinson (2016: 167-168), unlike Wilson, Curran, and Walton, is wary of the appeal to indeterminacy in this context (for a criticism of indeterminacy-based defenses of Imagining Seeing, see also Gaut 2010: 209-217). According to Levin-

9. A variant of Walton's approach has been recently proposed by Manuel García-Carpintero (2019), who argues that works of fiction mandate us to form two kinds of imaginings, namely, "constitutive" imaginings, which concern the fictional world-or "story world", as Walton calls it - and "ancillary" imaginings, which do not do so. Yet, ancillary imaginings have phenomenological relevance and, as imaginings, they concern a world different from the actual one-a world that corresponds to what Walton calls "game-world". If this is right, an account of film experience that relies on García-Carpintero's distinction between "constitutive" and "ancillary" imaginings would face difficulties with Disconnection just as Walton's account does. 
son, replying to the objections to Imagining Seeing by resorting to indeterminacy is not sufficient:

This reply helps, certainly; but without, I think, wholly dissolving the resistance to imaginary cinematic seeing for which Currie offers grounds. For some of the threatened presuppositions or implications of our imaginary seeing in films are so glaring, so salient, that it would seem the participating viewer would have to confront them, deal with them in some way in his mental economy, and not merely by omitting or ignoring them. (2016: 167)

Thus, Levinson proposes to treat the spectator's imaginary seeing as an experience of seeing from an unoccupied standpoint:

what I am proposing is that on a background level we simply imagine that something or other-some mechanism, perhaps, or some marvelous power - is facilitating our seeing as if from a given point without our actually being at that point. (2016: 168)

Still, once again, there is a difficulty with Disconnection. Even though the spectator does not occupy the standpoint from which the scene is observed, a spatiotemporal connection is needed in order to transfer information from that standpoint to her actual standpoint. Levinson himself acknowledges this when he writes:

I suppose it is part of one's imagining at such times that one is somewhere unspecified in the space of the film's events, since one is makebelievedly in one-way causal relation to what is shown-given to see $X$ is to be causally affected by $X$-but this is a 'somewhere' outside the possibility of two-way interaction with the events observed. (2016: 168)

Specifying that the spectator imagines being "somewhere unspecified in the space of the film's events" helps one to avoid violating Disconnection, but requires the further effort of imagining ourselves to be inhabitants of the same fictional world in which fictional events occur. This is an imaginative effort that we do not seem to make while watching fiction films.

In sum, treating the spatiotemporal relation between scene and spectator as having an indeterminate explanation (as Wilson, Curran, and Walton do) or a quasi-magical explanation (as Levinson does) cannot effectively fit with Disconnection. The problem is not the explanation of the relation between scene 
and spectator, but the relation itself. If we want to satisfy Disconnection, we need to rethink the nature of this relation. Specifically, we need to disentangle the notion of perceptual experience from a perceptual access provided by a spatiotemporal route. In the next section, I will propose a new thesis of imagination and film experience that aims to fulfill this need. This thesis can preserve the explanatory advantages of Imagining Seeing but, unlike the latter, can also satisfy Disconnection.

\section{The Imagining Impersonal Seeing Thesis}

The two contrasting accounts just analyzed have opposite pros and cons. On the one hand, Impersonal Imagining succeeds in satisfying Disconnection but finds it hard to deal with Seeing-in and Collapse, that is, to deal with the peculiar phenomenology of film experience as a perceptual experience of fictional events. On the other hand, Imagining Seeing succeeds in fitting with this peculiar phenomenology but has difficulties with Detachment (in the case of the face-to-face interpretation) and with Disconnection (in the case of the "Mediated Version"). Can there be an account that fits well with all the four requirements?

One can affirmatively answer this question if one acknowledges an imaginary way of perceiving that both Impersonal Imagining and Imagining Seeing overlook. According to Impersonal Imagining, the spectator perceives pictures (or, at most, actors and staging) without imagining perceiving the fictional events. According to Imagining Seeing, the spectator imagines perceiving fictional events in ways that are also available to us in our actual world: either face-to-face perceiving or pictorial transparent perceiving. By contrast, according to the thesis that I propose, namely Imagining Impersonal Seeing, the spectator imagines perceiving in an impersonal way that is not available to us in our actual world, but is nevertheless imaginable.

The core idea is that the spectator imagines being something different from herself. Here is the main difference with respect to Imagining Seeing. The spectator does not imagine that she herself is enjoying a face-to-face experience of fictional events or that she herself is watching a fictional recording of fictional events. In the imaginative project highlighted by Imagining Impersonal Seeing, the spectator is transformed into something else.

This imaginative transformation has significant analogies with the issue of imagining being another person - an issue discussed in contemporary philosophy under the rubric "imagination and the self" (see Ninan 2016). Following Bernard Williams's (1973) seminal paper on this topic, we can characterize the experience of imagining being Napoleon as an experience in which the subject associates her "Cartesian self" to Napoleon's "empirical self". That is to say that 
the subject conceives of herself as a disembodied and empty center of consciousness, and associates the latter with Napoleon's history, body and experiences.

However, Williams argues that we cannot have such imaginings. He does so on the basis of two assumptions; namely, (1) that only what is possible can be imagined, and (2) that the Cartesian self is an impossible entity. Combining (1) and (2), Williams concludes that the Cartesian self cannot be included in the imagined content. Yet, both (1) and (2) are questionable assumptions. It is not evident that the Cartesian self is an impossible entity (see Vendler 1984: 113118), and the entailment from imaginability to possibility is not evident either (see Ninan 2016: 276-277). ${ }^{10}$

Especially in our engagement with fiction, imagination does not seem to be as constrained by epistemological requirements as Williams assumes. Following Zeno Vendler (1984: 106-111), I hypothesize that, when one reads a narrative about a person and imagines being that person, one conceives of oneself as a pure potential for experiences, thereby imaginatively associating such potential to the experiences of another person. ${ }^{11}$ Interestingly, conceiving of oneself as a pure potential for experiences enables one to associate this potential not only to a person but also to an impersonal subject. The latter, unlike a person, is not individuated by a body. It is individuated just by a unified temporal series of experiences.

On the one hand, the impersonal subject differs from the Cartesian self since the latter is a pure potential for experiences whereas the former is individuated by a particular series of experiences. On the other hand, the impersonal subject differs from the empirical self of a person since the latter is individuated by its body and its experiences whereas the former is individuated only by its experiences. We might say that the impersonal subject is a quasi-empirical selfempirical in virtue of actually having experiences; quasi since its experiences are not embodied.

Drawing on this notion of impersonal subject, Imagining Impersonal Seeing states that the spectator of a fiction film imagines herself to be an impersonal subject individuated by the unified series of perceptual perspectives that the

10. It is worth noting that the claim that we can imagine being Cartesian selves does not entail the claim that we are Cartesian selves. What is under discussion here is not the ontological claim that there are disembodied subjects of experience but rather the psychological claim that one can imagine being such a subject. In his book Descartes' Baby (2004), Paul Bloom brings empirical evidence in favor of the imaginability of the Cartesian self, showing that very young children instinctively endorse Cartesian dualism: "babies see the world as containing both physical things, which are governed by principles such as solidity and gravity, and immaterial minds, which are driven by emotions and goals. Babies are natural-born dualists" (2004: xiii).

11. In other words, one can conceive of oneself as an "ungrounded disposition" to have experiences. Roger Scruton (2009: 53-60) characterizes an "ungrounded disposition" as a disposition that boils down to a brute fact instead of depending on more basic physical features. 
film provides her with. The impersonal spectator, so understood, is a merely temporal series of experiences, a subjective perceptual route through an objective fictional world. ${ }^{12}$

Vendler (1984:43) considers a case similar to that of the impersonal spectator when he distinguishes two ways one can imagine oneself doing something, for example, swimming in the ocean. He contrasts "objective imagination", which concerns what one would look like while swimming in the ocean, with "subjective imagination", which concerns what swimming in the ocean would be like. While the latter requires that one imagines oneself as an embodied person who swims in the ocean, the former requires that one imagines oneself as a disembodied subject who, from a given perspective, observes an embodied person swimming in the ocean. In objective imagination, one imagines being a sort of impersonal spectator of events in which oneself may be involved as a person..$^{13}$ Likewise, according to Imagining Impersonal Seeing, the spectator of a fiction film imagines being the impersonal spectator of the events in which fictional characters are involved.

The impersonal spectator is not a person having a place in space. Neither is the impersonal spectator a ghost, that is, a subject of experience who lacks a material body but has nevertheless a place in space. The impersonal spectator has no place in space at all, though she can perceive events that take place in space. What individuates the impersonal spectator as a subject is nothing but a unified temporal series of perceptual episodes.

If existing means having a place in a spatiotemporal system, then the impersonal spectator, who lacks a place in space, does not exist. But, if this is the case, how could one imagine not existing? We can answer this question if we consider a different meaning of existence, namely, being involved in some relation. ${ }^{14}$ The impersonal spectator does not exist according to the spatiotemporal conception of existence but somehow exists according to the relational conception. In spite of lacking a place in the spatiotemporal system that constitutes the fictional world, the impersonal spectator is affected by the fictional events in virtue of

12. If this is right, the putative "Descartes' error" (see Damasio 1994) about our experience of the actual world leads us to a suitable theory of our experience of fiction films.

13. Michael Martin makes a similar point when he writes: "The point of view within the imagined scene is notoriously empty enough that one can in occupying that point of view imagine being someone other than one actually is. [ . . . So, in using imagery within an imaginative project it is open to one to exploit the point of view within the visualising, either as one's own, or as someone else's, whose point of view one make-believedly occupies" (2002: 411).

14. On the one hand, the "relational" conception of existence can be traced back to Plato's "Eleatic Principle", as David Armstrong (1997: 41) points out. On the other hand, the "spatiotemporal" conception of existence has Aristotelian and Kantian roots, as stressed by Peter Strawson (1959; 1966). 
perceiving them. This relation, which enables impersonal perception, provides the impersonal spectator with some relational existence..$^{15}$

However, this relation does not require any spatiotemporal route. It only requires pure counterfactual dependency of the perceptual episode on the perceived event; if the event had not occurred, that perceptual episode would not have occurred, and that is all. The impersonal spectator can thus observe fictional events without any spatiotemporal connection to them. This enables the Imagining Impersonal Seeing thesis to satisfy Disconnection.

Since the impersonal spectator exists only in virtue of the counterfactual dependency of its perceptual episodes on the events that occur in the fictional world, nothing would be subtracted from that world by the removal of the impersonal spectator. Thus, impersonal perception is an experience of a world in which the subject of experience does not exist in the way things normally exist, that is, by making some difference in the world they inhabit. We usually treat fictional characters as nonexistent entities or, at least, as entities that are "shy of existence", to borrow Nathan Salmon's expression. ${ }^{16}$ However, when we perceive the fictional world from the perspective of the impersonal spectator we are rather inclined to treat fictional characters as provided with full-fledged spatiotemporal existence while finding ourselves to be "shy of existence". ${ }^{17}$

The thesis that I propose is sympathetic with both Impersonal Imagining and Imagining Seeing, but for different reasons. On the one hand, Imagining Impersonal Seeing is sympathetic with Imagining Seeing in characterizing film experience as a sort of imagining seeing, but it does not require a spatiotemporal connection between the fictional world and the actual world, thereby fitting with both Detachment and Disconnection. On the other hand, Imagining Impersonal Seeing is sympathetic with Impersonal Imagining in stressing that our experience of the story told is somehow impersonal. Just as Impersonal Imagining, my thesis does not posit any imaginary relation between the fictional world and the spectator as an embodied subject, namely, as a person. Nevertheless, unlike Impersonal Imagining, my thesis fits with both Seeing-in and Collapse, preserving the perceptual specificity of film experience.

15. The perceptual relation that warrants the impersonal spectator's relational existence can be treated as a causal relation, provided that one conceives of causation as mere counterfactual dependency (see Chalmers 2005). If, instead, one thinks that causation requires a spatiotemporal route that links the cause to the effect (see Salmon 1984), the perceptual relation that constitutes impersonal perception cannot be a causal relation. Thanks to a referee for leading me to clarify the role of causality in my account.

16. Specifically, Salmon characterizes Meinongian objects as having a "lower-class ontological status, a sort of being shy of existence" (2005: 63).

17. By "shy of existence", here I mean existing only in virtue of being perceptually affected by events, without having any spatiotemporal location or causal power. 
Ultimately, Imagining Impersonal Seeing combines the explanatory power of Impersonal Imagining and Imagining Seeing thereby solving their respective problems. If, in the framework of the imaginative project we deploy as spectators of fiction films, we wonder how we can perceive events occurring in a world that is not ours, we must resort to Imagining Impersonal Seeing in order to satisfactorily make sense of our experience.

\section{Appreciation}

In addition to the four requirements highlighted in the first part of the paper, there are two other basic features that an account of film experience must accommodate. First, films can be objects of aesthetic appreciation. Second, films can elicit emotions. In what follows, I show how Imagining Impersonal Seeing can deal with appreciation. I shall address the issue of emotions in the next section.

Appreciating a film surely requires treating the series of shots that constitutes it as the outcome of some agency, typically that of a filmmaker. Yet, one might object that Imagining Impersonal Seeing treats that series of shots as the series of perspectives of an impersonal spectator, not as the outcome of some agency. Therefore, one might conclude, Imagining Impersonal Seeing cannot accommodate film appreciation.

I address this objection by conceiving of impersonal perception as one component of a pictorial experience that is constituted by two complementary components. Specifically, borrowing Wollheim's (1998) terminology (without being committed to his account of pictorial perception), I treat film experience as "twofold", that is, as constituted by a "configurational fold", which consists of the ordinary (personal) perception of the screening, and a "recognitional fold", which consists of the impersonal perception of the events depicted. ${ }^{18}$

Although film experience actually is twofold pictorial perception, the imagination can emphasize the recognitional fold at the expense of the configurational fold, thereby turning pictorial perception into impersonal perception. In fact, there is no way of directly enjoying impersonal perception in our physical world, and yet we can emulate it by imaginatively favoring one fold, namely the

18. Following Mohan Matthen (2005), I interpret the "configurational fold" as the experience of the egocentric space in which the film is screened, and the "recognitional fold" as a perceptual perspective on a space detached from the spectator's body. Moreover, following Currie (2018), I shall not commit myself to the claim that pictorial experience requires simultaneous attention to the content of both folds, that is, "simultaneous attention to what is seen and to the features of the medium" (Wollheim 1980: 142). As Currie points out, films have a tendency "to focus us exclusively on features of what is represented and not at all on features of the image surface" (2018: 193). 
recognitional fold, of the actually twofold pictorial experience. The darkness of the movie theater surely helps us in carrying out such a task.

Nevertheless, even if the recognitional fold tends to dominate our film experience, the configuration fold keeps running parallel and we can pay attention to it whenever we want. I argue that mobilizing the configurational fold is precisely what we do when we aesthetically appreciate a film. From this perspective, the aesthetic appreciation of a film consists in tracing the impersonal perception we enjoy in the recognitional fold back to its actual roots in the configurational fold.

Consider, for example, film shooting and editing. Impersonal perception is delivered from the law of continuity that governs all our movements in time and space. While ordinary perception provides us with a subjective perspective of the objective world that is determined by the spatiotemporal location of our body in that world, impersonal perception is not constrained by such determination. Thus, the impersonal spectator can jump from one perspective on fictional events to another without being forced to cover the spatial (or spatiotemporal) distance between the two standpoints corresponding to those perspectives. ${ }^{19}$ Yet, in appreciating a film, we do not limit ourselves to enjoying this special way of perceiving. Rather, we trace it back to the agency of a maker, thereby recognizing the shifts of perspective as grounded in a configuration of shots which is the outcome of film shooting and editing. ${ }^{20}$ We thus appreciate a fiction film by discovering where the experience of fictional events that we are enjoying comes from. A fiction film is a work presenting us a world, and by impersonally perceiv-

19. As a consequence of this, the temporal series of perceptual perspectives on the fictional world that constitutes the impersonal spectator has a temporal order of its own, which is independent of the spatiotemporal order of the fictional world. By contrast, the series of our ordinary perceptual experience has a temporal order that strictly depends on the temporal position of our body in the spatiotemporal order of the actual world. Although impersonal perception is a kind of perceptual experience that we cannot enjoy in everyday life, we could experience (and arguably, sometimes, we do experience) it in our dreams. This can shed some light on the relationship between film experience and dreaming experience, which has been emphasized by several scholars (see Langer 1953; McGinn 2005; Metz 1982; Münsterberg 1916; Sparshott 1971).

20. Christian Metz (1982) argues that, in addition to the "secondary" identification with characters, film experience involves a more fundamental "primary" identification, which in his view consists in the identification with the camera. Metz's insight puts us on the right track, but this is not the whole story. The camera is just the technical device that allows us to achieve the primary identification, but what we identify with is the impersonal spectator, not the camera. That is why people can enjoy fiction films even though they have no idea how the camera works. This is, for instance, the way in which I enjoyed fiction films when I was a child. However, if one wants to turn one's enjoyment of a film into full-fledged appreciation, then Metz is right: one should acknowledge that what grounds one's primary identification with the impersonal spectator is the camera. Thanks to a referee for leading me to consider the dialectic between the impersonal spectator and the camera. 
ing the world (focusing on the recognitional fold) we come to personally appreciate the work (paying attention also to the configurational fold).

\section{Emotions}

While watching films, we do not only perceive fictional events but also feel emotions concerning them. We anticipate, we regret, we fear, we pity. Yet, one might object, Imagining Impersonal Seeing leaves no room for all of this, since only an embodied person can have emotions. How can the spectator make sense of her emotions if she imagines herself to be an impersonal spectator?

My reply is that, although many ordinary emotions involve a bodily response, one can conceive of emotions that do not so. ${ }^{21}$ Just as the spectator can imagine herself to have impersonal perceptual episodes which do not require a body, she can imagine herself to have "impersonal" emotions that supplement her impersonal perception with an evaluative dimension. ${ }^{22}$

At this point, one might still object that there are two kinds of emotions that are relevant to film experience but not available to the impersonal spectator. First, emotions that essentially involve bodily reactions, as for instance the startle response (see Smith 2013: 31-37); let us call them body emotions. Secondly, emotions directed toward the film as an artifact, or artifact emotions, as Ed Tan (1996: 65-66) calls them; for instance, an emotion of admiration directed towards an amazing camera movement.

In order to reply to this objection, let me recall the strategy that I deployed in the discussion of appreciation, when I pointed out that impersonal perception occurs in the recognitional fold of a twofold pictorial experience. Even though the imaginative project supported by the darkness of the movie theater favors the recognitional fold, films can sometime lead the spectator to turn her impersonal perception into full-fledged pictorial perception, which is a kind of personal

21. In this sense, I am sympathetic with Walton's (1990: 251) idea that emotions directed toward fictional entities are not "garden variety" emotions but rather fictional emotions, which share the phenomenological components of ordinary emotions that Walton calls quasi-emotions and yet, unlike ordinary emotions, are not intimately connected to motivation and action. However, my account departs from Walton's since I conceive of fictional emotions as the peculiar "impersonal" emotions of a disembodied subject, who enjoys impersonal perception.

22. This claim about emotions in fiction films is compatible with an evaluative conception of emotions as evaluations of perceptual (or, more generally, representational) contents (see Nussbaum 2001), as well as with a perceptual conception of emotions as perceptual experiences of evaluative properties (see Tappolet 2016). Moreover, this claim fits well with a specificity of the spectator's emotions that has been highlighted by Hopkins (2010: 211): these emotions are "scenedirected", not "self-directed"; they appraise what one perceives, not what one does or what one is. As an impersonal spectator, one cannot do anything and yet one can perceive and emotionally appraise the content of one's perception. 
experience, in which the subject's body can show up. I argue that such phenomenological shift occurs when the spectator feels body emotions or artifact emotions. Specifically, body emotions turn impersonal perception into personal perception since our body does not limit itself to implement such emotional experience but shows up in its phenomenology - and our body is what constitutes us as persons (instead of as pure series of experiential episodes). Likewise, artifact emotions turn impersonal perception into personal perception since they lead us to pay attention also to the configurational fold, which involves a perception of the screening as an event occurring in front of our body.

While the latter kinds of emotions could not be properly enjoyed by relying only on impersonal perception, there is another emotion that, I contend, is peculiar to impersonal perception and can be properly enjoyed only within it. This emotion is the sense of puzzlement that the spectator feels when fictional characters "break the fourth wall" by looking at her. Film scholars calls this phenomenon "the look at the camera", treating it as an instance of a more general phenomenon called "metalepsis", which consists in crossing boundaries between distinct narrative levels (see Bracker 2017). I abide by this terminology even though, as Marc Vernet points out,

The expression 'the look at the camera' is particularly troublesome because it tries to explain in terms of the moment of filming an effect that is produced in the moment of the film's projection: namely, the spectators's impression that a character in the diegesis, or an actor during the filming, is looking directly at them. (1989: 49)

The impression elicited by the look at the camera usually involves a disturbing sense of puzzlement, and that is why the look at the camera is ruled out by the so-called "grammar" or "code" of Hollywood films. However, such sense of puzzlement can become an aesthetic resource for creative filmmakers. For instance, Jean Renoir skillfully exploits the look at the camera in A Day in the Country (1936: see picture A), and so does Ingmar Bergman in Summer with Monika (1953: see picture B), Jean-Luc Godard in Breathless (1960: see picture C), and Alfred Hitchcock in Psycho (1960: see picture D).

An account of film experience should explain why the look at the camera elicits a peculiar sense of puzzlement. Yet, some of the main theses about imagination and perception in film experience arguably have trouble in doing so. Specifically, No Imagining and Impersonal Imagining find it hard to explain why the spectator is puzzled by seeing fictional characters looking at her since both these theses assert that the spectator does not imagine seeing fictional characters. If the spectator does not imagine herself to be related to fictional events but only constructs mental models of them (as No Imagining states) or impersonally imagines 
them (as Impersonal Imagining states), how could she be puzzled by the way in which the look at the camera affects her relation to fictional events?

By stating that the spectator imagines not only fictional events but also her relation to them, Imagining Seeing seems to be in a better position to explain why the look at the camera elicits puzzlement from the spectator. Yet, some versions of this thesis might face difficulties in developing the explanation. If, for instance, the spectator imagines seeing a recording of fictional events, as Wilson's "Mediated Version" contends, the look at the camera surely would not be puzzling. The reason is that the look at the camera elicits a sense of puzzlement only in fiction films, in which the camera is not part of the fictional world, and thus the look cannot be experienced as being directed at the camera. The look at the camera is, instead, an ordinary and harmless mode of representation in recordings such as those of documentaries or television news, in which it can be experienced for what it actually is, namely, the look of a person at the camera that is filming her. Therefore, the specificity of the look at the camera in fiction films cannot be satisfactorily explained by an account such as Wilson's, which claims that we experience fiction films in the same way as we experience recordings. ${ }^{23}$ Other versions of Imagining Seeing, for which the spectator imagines perceiving fictional events in the way she ordinarily perceives real events, confront similar problems in explaining the look at the camera, inasmuch as in ordinary perception we usually are not puzzled when the person whom we are looking at looks at us.

Imagining Impersonal Seeing, instead, can offer a satisfactory explanation of the phenomenon. The look at the camera elicits a sense of puzzlement because the spectator of fiction films imagines being an impersonal subject who, as such, can see fictional events without being seen by fictional characters. The spectator is thus puzzled by the fact that fictional characters are doing something that in principle they could not do, namely, looking at her in spite of her disembodied nature.

"How can you see me? I have no body!" Here is the spectator's puzzlement in response to the look at the camera. This account fits well with the fact that the look at the camera, when used for expressive purposes, often is the look of a character who finds himself or herself in a somehow exceptional state of the

23. On the other hand, Wilson's account fits well with those fiction films such as The Blair Witch Project (1999) that present themselves as filmed though a fictional camera. In those films, usually called "mockumentaries", the look at the camera is not puzzling since it literally corresponds to a look at the camera in the fictional world. Thanks to a referee for drawing my attention to mockumentaries, which I take to be a borderline case of fiction films precisely because they elicit a special kind of film experience-an experience as of a documentary-which differs from the standard experience of fiction films. Nevertheless, Imagining Impersonal Seeing can accommodate mockumentaries by stating that in that case the spectator does not imagine impersonally seeing the events depicted but rather imagines impersonally seeing the screening of a documentary. 
mind, which might lead him or her to imaginatively address a fictional interlocutor. The best example I know of this phenomenon can be find in the TV show $\mathrm{Mr}$. Robot (2015-2019: see picture E), whose main character recurrently looks at the camera and speaks to it, as if the spectator was his imaginary friend. Remember that Imagining Impersonal Seeing conceives of the impersonal spectator as having an ontological status in the fictional world that is pretty much close to the "ontological shyness" that characterizes fictional characters and other imaginary creatures when considered from the perspective of our actual world (cf. Salmon 2005: 63). Shy people, one might say, feel uncomfortable when they are looked at, and being shy of existence makes no exception in this respect.

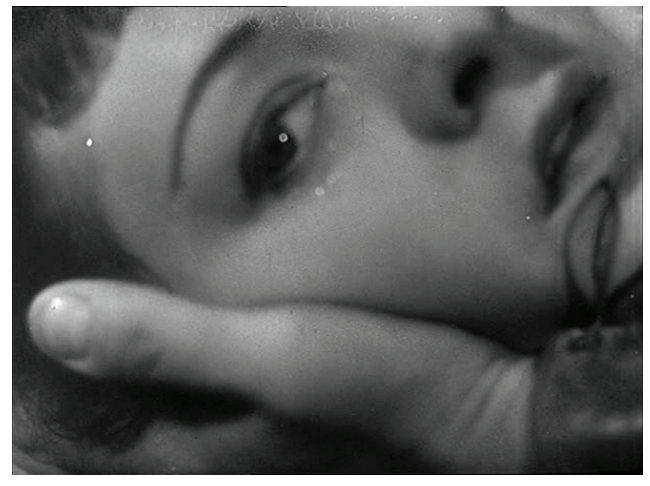

Picture A

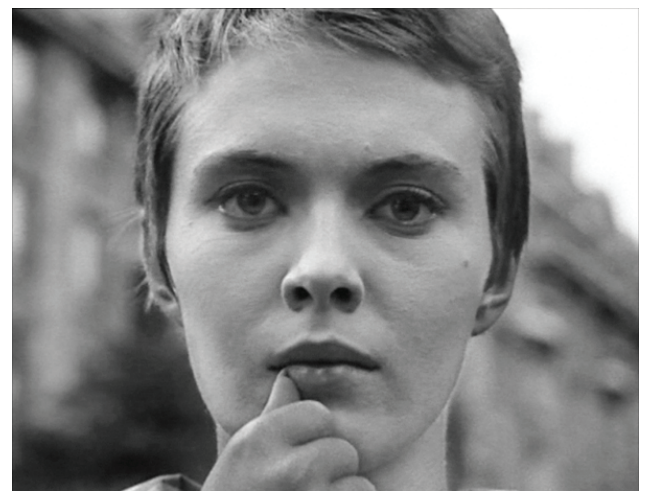

Picture C

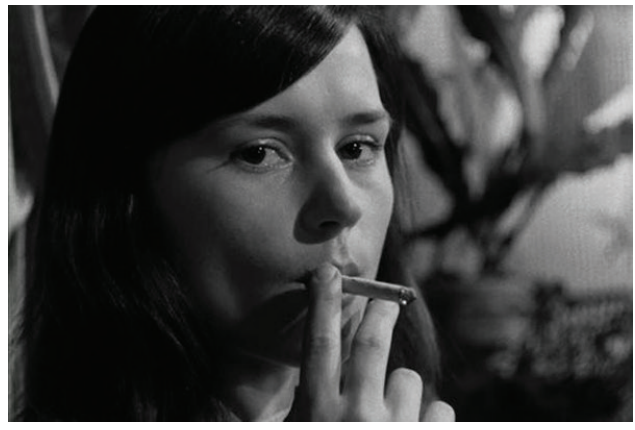

Picture B

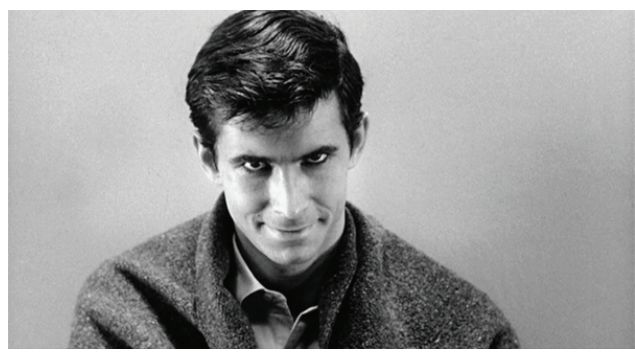

Picture D

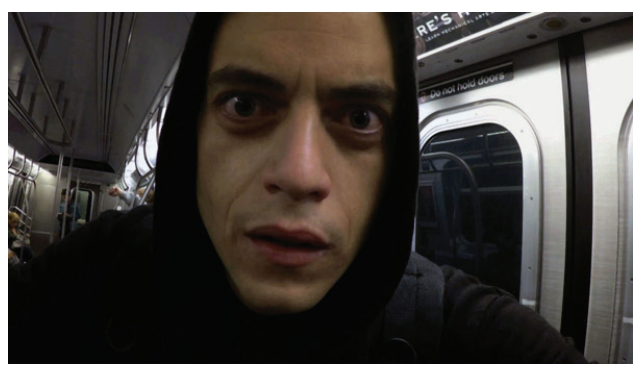

Picture E 


\section{Conclusion}

In this paper I have highlighted four requirements that an account of film experience must satisfy, and I have argued that my proposal, namely Imagining Impersonal Seeing, satisfies all these requirements whereas its competitors cannot do so. The thesis I propose states that the film spectator imagines perceiving fictional events in an impersonal way. This contrasts not only with No Imagining, which denies the essential role of the imagination in film experience, but also with Impersonal Imagining, which denies that the spectator imagines perceiving events, and even with Imagining Impersonal Seeing, which states that the spectator imagines perceiving events in a personal way.

However, there are two accounts of film experience, namely Lopes's (1998) variant of Impersonal Imagining and Levinson's (2016) variant of Imagining Seeing, which are closer to my proposal than the other versions of those theses. In this last part of the paper, I shall highlight the novelty of my proposal with respect to these two competitors.

Lopes agrees with Currie that we imagine fictional events without imagining our personal relation to them, adding that "film experience is impersonal because it is a case of impersonal perceptual experience" (1998: 353). The idea is that film experience is a perceptual experience that represents a scene from a viewpoint without representing the spectator as being at that viewpoint. Therefore, film experience is impersonal in the sense that it does not represent the spectator as the subject who is perceiving. ${ }^{24}$ That is why, for Lopes, we can impersonally imagine fictional events not in spite of perceiving them, as Currie suggests, but rather in virtue of perceiving them, since our pictorial perception of them, as such, does not represent us as perceiving subjects.

However, Lopes moves too quickly from the premise that film experience represents events as perceived from an unoccupied viewpoint to the conclusion that it does not represent the spectator as the subject who is perceiving. The hidden premise of Lopes's argument is the presupposition that representing one's body as occupying the viewpoint is the only way in which one can represent oneself as the subject of a perceptual experience. Yet, this claim is questionable. ${ }^{25}$ In the specific case of film experience, the phenomenon of the look at the camera suggests that we can represent ourselves in relation to the events perceived without representing our body as occupying the corresponding viewpoint. If this is right, our imaginative engagement with fiction films involves a special way of representing ourselves (as I claim) rather than no representation of ourselves (as Lopes claims).

In his variant of Imagining Seeing, Levinson (2016: 168) specifies such a special way of representing ourselves, contending that we imagine having some 
special mechanism or power that enables us to perceive from viewpoints we do not occupy. Yet, I argue, we do not need to engage in such cumbersome imaginings about some mysterious mechanism or power. We would need to do so only if we kept conceiving of ourselves as embodied subjects. If, instead, we imagine being disembodied subjects, we do not need to imagine having some special power or mechanism anymore. We can perceive events from viewpoints that we do not occupy just in virtue of our imaginary nature of impersonal spectators. As Vernet (1989:54) has aptly noted, "In order to be all-seeing, the spectator does not need to be everywhere: the spectator only needs to be nowhere".

\section{Acknowledgments}

This essay has grown from years of conversation with several colleagues. In particular, I would like to thank audiences at conferences in Sheffield, Macau, Upsala, Paris, and Prague for discussion of related material. Special thanks to Filippo Contesi, Manuel García-Carpintero, Dominic Gregory, Uriah Kriegel, Jerrold Levinson, Louis Rouillé and Daniela Tagliafico for critiques, suggestions and advises. I am very grateful also to the anonymous referees for Ergo and the area editor of this journal for their insightful comments.

\section{References}

Alsmith, Adrian J. T. (2017). Perspectival Structure and Agentive Self-Location. In Frederique de Vignemont and Adrian J. T. Alsmith (Eds.), The Subject's Matter: SelfConsciousness and the Body (263-287). MIT Press.

Armstrong, David (1997). A World of States of Affairs. Cambridge University Press. https://doi.org/10.1017/CBO9780511583308

Bloom, Paul (2004). Descartes' Baby. Basic Books.

Bracker, Jacobus (2017). The Borders of Metalepses and the Borders of the Image. In Lars C. Grabbe, Patrick Rupert-Kruse, and Norbert M. Schmitz (Eds.), Bildverstehen. Spielarten und Ausprägungen der Verarbeitung multimodaler Bildmedien (93-109). Büchner-Verlag.

Byrne, Alex (2010). Recollection, Perception, Imagination. Philosophical Studies, 148(1), 15-26. https://doi.org/10.1007/s11098-010-9508-1

Carroll, Noël (1996). Theorizing the Moving Image. Cambridge University Press.

Carroll, Noël (2009). Narration. In Paisley Livingston and Carl Plantinga (Eds.), The Routledge Companion to Philosophy and Film (196-206). Routledge.

Chalmers, David (2005). The Matrix as Metaphysics. In Christopher Grau (Ed.), Philosophers Explore the Matrix (132-176). Oxford University Press.

Curran, Angela (2016). Fictional Indeterminacy, Imagined Seeing, and Cinematic Narration. In Katherine Thomson-Jones (Ed.), Current Controversies in Philosophy of Film (99-114). Routledge. https://doi.org/10.4324/9781315764887-6 
Currie, Gregory (1995). Image and Mind. Cambridge University Press. https://doi. org/10.1017/CBO9780511551277

Currie, Gregory (2004). Can There Be a Literary Philosophy of Time? In Arts \& Minds (84-104). Clarendon. https://doi.org/10.1093/0199256284.003.0006

Currie, Gregory (2010). Bergman and the Film Image. Midwest Studies in Philosophy, 34(1), 323-339. https://doi.org/10.1111/j.1475-4975.2010.00199.x

Currie, Gregory (2018). Visually Attending to Fictional Things. In Fabian Dorsch and Fiona Macpherson (Eds.), Perceptual Imagination and Perceptual Memory (186208). Oxford University Press. https://doi.org/10.1093/oso/9780198717881.003.0009

Currie, Gregory and Ian Ravenscroft (1997). Mental Simulation and Motor Imagery. Philosophy of Science, 64(1), 161-180. https://doi.org/10.1086/392541

Currie, Gregory and Ian Ravenscroft (2002). Recreative Minds: Imagination in Philosophy and Psychology. Clarendon Press. https://doi.org/10.1093/acprof:oso/9780 198238089.001.0001

Damasio, Antonio (1994). Descartes's Error: Emotion, Reason and the Human Brain. Grosset and Putnam.

García-Carpintero, Manuel (2019). Normative Fiction-Making and the World of the Fiction. The Journal of Aesthetics and Art Criticism, 77(3), 267-279. https://doi. org/10.1111/jaac. 12660

Gaut, Berys (2010). A Philosophy of Cinematic Art. Cambridge University Press. https://doi.org/10.1017/CBO9780511674716

Hopkins, Robert (2008). What Do We See in Film? The Journal of Aesthetics and Art Criticism, 66(2), 149-159. https://doi.org/10.1111/j.1540-6245.2008.00295.x

Hopkins, Robert (2010). Moving because Pictures? Illusion and the Emotional Power of Film. Midwest Studies in Philosophy, 34(1), 200-218. https://doi.org/10.1111/j.1475-4975.2010.00208.x

Kriegel, Uriah (2015). Perception and Imagination: A Sartrean Account. In Sofia Miguens, Gerhard Preyer, and Clara Bravo Morando (Eds.), Prereflective Consciousness: Early Sartre in the Context of Contemporary Philosophy of Mind (257-288). Routledge.

Langer, Susanne K. (1953). Feeling and Form. Scribner.

Levinson, Jerrold (2016). Seeing, Imaginarily, at the Movies. In Aesthetic Pursuits: Essays in Philosophy of Art (163-173). Oxford University Press. Updated version of the 1993 essay published in The Philosophical Quarterly, 43(170), 70-78. https://doi. org/10.1093/acprof:oso/9780198767213.003.0013

Liao, Shen-yi and Tamar Gendler (2019). Imagination. In Edward N. Zalta (Ed.), The Stanford Encyclopedia of Philosophy (Spring 2019 Edition). https://plato.stanford. edu/archives/spr2019/entries/imagination/

Lopes, Dominic (1998). Imagination, Illusion and Experience in Film. Philosophical Studies, 89(2/3), 343-353. https://doi.org/10.1023/A:1004201516642

Martin, Michael G. F. (1992). Sight and Touch. In Tim Crane (Ed.), The Contents of Experience: Essays on Perception (196-215). Cambridge University Press. https://doi. org/10.1017/CBO9780511554582.010

Martin, Michael G. F. (2002). The Transparency of Experience: Mind \& Language, 17(4), 376-425. https://doi.org/10.1111/1468-0017.00205

Matravers, Derek (2014). Fiction and Narrative. Oxford University Press. https://doi. org/10.1093/acprof:oso/9780199647019.001.0001

Matthen, Mohan (2005). Seeing, Doing, and Knowing. Oxford University Press. https:// doi.org/10.1093/0199268509.001.0001 
McGinn, Colin (2005). The Power of Movies: How Screen and Mind Interact. Pantheon.

Metz, Christian (1982). The Imaginary Signifier: Psychoanalysis and the Cinema. Indiana University Press. https://doi.org/10.1007/978-1-349-05103-8

Münsterberg, Hugo (1916). The Photoplay: A Psychological Study. Appleton.

Ninan, Dilip (2016). Imagination and the Self. In Amy Kind (Ed.), The Routledge Handbook of Philosophy of Imagination (274-285). Routledge.

Nussbaum, Martha C. (2001). Upheavals of Thought: The Intelligence of Emotions. Cambridge University Press. https://doi.org/10.1017/CBO9780511840715

Salmon, Wesley (1984). Scientific Explanation and the Causal Structure of the World. Princeton University Press.

Salmon, Nathan (2005). Nonexistence. In Metaphysics, Mathematics, and Meaning: Philosophical Papers, Volume I (50-90). Oxford University Press. https://doi.org/10.1093/0199284717.003.0003

Scruton, Roger (2009). Sounds as Secondary Objects and Pure Events. In Matthew Nudds and Casey O'Callaghan (Eds.), Sounds and Perception: New Philosophical Essays (50-68). Oxford University Press. https://doi.org/10.1093/acprof:oso/9780199282968.003.0003

Smith, Murray (2013). The Pit of Naturalism: Neuroscience and the Naturalized Aesthetics of Film. In Ted Nannicelli and Paul Taberham (Eds.), Cognitive Media Theory (27-45). Routledge.

Sparshott, Frances (1971). Vision and Dream in the Cinema. Philosophic Exchange, 2(1), 111-122.

Stecker Robert (2013). Film Narration, Imaginative Seeing, and Seeing-In. Projections: The Journal for Movies and Mind, 7(1), 147-154.

Strawson, Peter F. (1959). Individuals. Methuen.

Strawson, Peter F. (1966). The Bounds of Sense: An Essay on Kant's Critique of Pure Reason. Methuen.

Strawson, Peter F. (1974). Causation in Perception. In Freedom and Resentment (73-93). Methuen.

Tan, Ed S. (1996). Emotion and the Structure of Narrative Film: Film as an Emotion Machine. Lawrence Erlbaum.

Tappolet Christine (2016). Emotions, Values, and Agency. Oxford University Press. https://doi.org/10.1093/acprof:oso/9780199696512.001.0001

Turvey Malcom (2019). (Collapsed) Seeing-In and the (Im-)Possibility of Progress in Analytic Philosophy (of Film). In Christina Rawls, Diana Neiva, Steven S. Gouveia (Eds.), Philosophy and Film: Bridging Divides (11-25). Routledge. https://doi.org/10.4324/9780429435157-2

Vendler, Zeno (1984). The Matter of Minds. Clarendon Press.

Vernet, Marc (1989). The Look at the Camera. Cinema Journal, 28(2), 48-63. https://doi.org/10.2307/1225117

Voltolini, Alberto (2015). A Syncretistic Theory of Depiction. Palgrave Macmillan. https://doi.org/10.1057/9781137263292

Walton, Kendall L. (1978). How Remote Are Fictional Worlds from the Real World? The Journal of Aesthetics and Art Criticism, 37(1), 11-23. https://doi.org/10.2307/430872

Walton, Kendall L. (1984). Transparent Pictures: On the Nature of Photographic Realism. Critical Inquiry, 11, 246-277. https://doi.org/10.1086/448287

Walton, Kendall L. (1990). Mimesis as Make-Believe: On the Foundations of the Representational Arts. Harvard University Press. https://doi.org/10.2307/431705 
Williams, Bernard (1973). Imagination and the Self. In Problems of the Self (26-45). Cambridge University Press. https://doi.org/10.1017/CBO9780511621253.005

Wilson, George M. (2011). Seeing Fictions in Film: The Epistemology of Movies. Oxford University Press. https://doi.org/10.1093/acprof:oso/9780199594894.001.0001

Wollheim, Richard (1980). Art and Its Objects: An Introduction to Aesthetics (2nd ed.). Harper and Row. https://doi.org/10.1017/CBO9781316286777

Wollheim, Richard (1998). On Pictorial Representation. The Journal of Aesthetics and Art Criticism, 56(3), 217-226. https://doi.org/10.2307/432361

Zeman, Adam, Michaela Dewar, and Sergio DellaSala (2015). Lives without Imagery-Congenital Aphantasia. Cortex, 73, 378-38o. https://doi.org/10.1016/j.cortex.2015.05.019 